\title{
Healthcare Consumption and Cost Estimates Concerning Swedish Women with Endometriosis
}

\author{
Hanna Grundström ${ }^{\text {a, b }}$ Gabriel Hammar Spagnoli ${ }^{a}$ Lena Lövqvist ${ }^{a}$ \\ Matts Olovsson ${ }^{\mathrm{a}}$

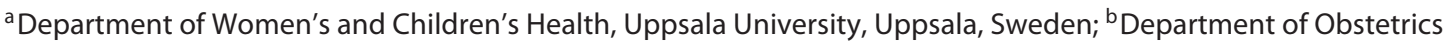 \\ and Gynecology in Norrköping, Linköping, Sweden
}

\section{Keywords}

Endometriosis - Healthcare consumption - Cost estimates . Absenteeism · Presenteeism · Chronic pelvic pain

\begin{abstract}
Introduction: Endometriosis is known for its substantial effect on women's wellbeing and quality of life. In order to evaluate disease burden, treatments and health services, assessments of healthcare consumption and cost estimates are necessary. Objectives: The aim of this study was to estimate healthcare consumption and annual cost per woman with endometriosis in Sweden and to examine healthcare consumption and costs in different age groups. Methods: A questionnaire was distributed to 400 members of the Endometriosis Association and to 400 randomly selected women with surgically confirmed endometriosis. Official statistics were obtained via correspondence, publications, and database searches. Results: Analysis of the 431 returned questionnaires showed that women under 30 years utilized more inpatient and outpatient care than older women. The mean annual cost among all women was EUR 8,768/woman. The direct healthcare cost of managing the disease was EUR
\end{abstract}

4,282, while the indirect cost was EUR 4,486. Absence from work was reported by $32 \%$ of the women, while $36 \%$ reported reduced time at work because of endometriosis. Conclusion: Our results confirm the substantial negative effect of endometriosis upon women's lives and their relatively high healthcare consumption.

(C) 2020 The Author(s)

Published by S. Karger AG, Basel

\section{Introduction}

Endometriosis, a gynecological disease defined as the presence of ectopic endometrial-like tissue [1], affects approximately $10 \%$ of women of reproductive age [2]. The disease is complex and heterogenic, and a combination of immunological, hormonal, genetic, and epigenetic factors may all be involved in the etiology [3]. The symptoms are variable and often nonspecific, which makes diagnosis of the condition challenging. A definitive diagnosis can only be made with a positive histological biopsy sample. For practical and economic reasons, this is not always possible, which could be a factor behind the observed diagnostic delay, especially in primary care [1]. The delay

$\begin{array}{ll}\text { karger@karger.com } & \text { (c) 2020 The Author(s) } \\ \text { Published by S. Karger AG, Basel } & \text { Karger } \\ \text { www.karger.com/goi } & \text { This is an Open Access article licensed under the Creative Commons } \\ \text { Aarger } & \begin{array}{l}\text { Attribution-NonCommercial-4.0 International License (CC BY-NC) } \\ \text { (http://www.karger.com/Services/OpenAccessLicense), applicable to } \\ \text { the online version of the article only. Usage and distribution for com- } \\ \text { mercial purposes requires written permission. }\end{array}\end{array}$

Hanna Grundström, RNM, PhD

Department of Health

Medicine and Caring Sciences

Linköping University, SE-581 83 Linköping (Sweden)

E-Mail hanna.grundstrom@liu.se 
can be up to 10 years from symptom onset to diagnosis [4-7].

Most endometriosis symptoms involve pain, which affects both quality of life and productivity [4], resulting in a significant financial impact. The direct healthcare costs of managing the disease (inpatient, outpatient, surgical, drug costs etc.,) and the indirect costs (loss of productivity at work) are substantial and have been the focus of 3 systematic literature reviews [8-10]. The most recent included 12 studies published between 2000 and 2013 from the USA, Austria, Belgium, Brazil, Canada, Finland, Germany, and Italy. Two of the studies included data from 10 countries. Because of great variation in methodology, healthcare systems, and costs, the direct and indirect cost estimates varied widely. The estimates of direct costs ranged between USD 1,109/woman/year in Canada to USD 12,118/woman/year in the United States. The indirect costs were also highest in the United States, at USD $15,737 /$ woman/year, while the lowest estimate was found in Austria, at USD 3,314 woman/year [10].

Information on healthcare consumption and estimates of costs is important in the work of clarifying disease burden and improving the efficiency of health-service consumption and treatments. In Sweden, no cost estimates are available, as far as we know. Therefore, the aim of this study was to estimate healthcare consumption and annual cost per woman with endometriosis in Sweden and to examine healthcare consumption and costs in different age groups.

\section{Material and Methods}

This article is based on material from a large retrospective cross-sectional study performed in Sweden in 2010 [11], in which a self-administered questionnaire was distributed to 400 randomly selected women with surgically confirmed endometriosis. They were attending 3 middle-sized gynecological clinics in Sweden, one large clinic and one endometriosis specialist clinic. The questionnaire was also sent to 400 members of the Endometriosis Association, Sweden. In total, 800 questionnaires were sent out.

The questionnaire was developed after 2 focus-group meetings with members of the Endometriosis Association and was inspired by a validated generic questionnaire, Short Form Health Survey 36 [12] (known as SF-36) and the disease-specific questionnaire Endometriosis Health Profile-30 [13]. It included 53 questions (1-12 months retrospective or questions such as "Have you ever...?" and "Are you presently... ?") divided into 6 categories: (a) physical and psychological symptom description, (b) contacts with physicians/ nurses, (c) treatment, (d) work/education patterns, (e) relationships and fertility, and (f) demographics. The questions covered the number of contacts and/or visits to general physicians, gynecologists, fertility specialists, midwives and nurses in primary care, planned hospital visits, visits to an emergency department, surgical procedures, and days in hospital as a result of endometriosis during the previous 12 months. For questions regarding inability to work, study, or perform everyday tasks because of endometriosis, the time period covered the previous 4 weeks in order to reduce recall bias. If the women did not respond to the questionnaire within 3 weeks, a reminder was sent.

Official statistics were obtained via correspondence, database searches, and publications from The Swedish Association of Pharmaceutical Industries, The National Board of Health and Welfare Statistics Sweden, The Swedish Insurance agency, The Swedish Association of Local Authorities and Regions, and The Swedish eHealth Agency.

\section{Cost Estimates}

All costs were originally obtained in connection with financial year 2010, except for drug costs, for which the financial year was 2015 , since no database for previous years was available. All costs (in euros) were recalculated to present-day (2019) values, taking the monetary inflation under consideration, unless otherwise specified.

Costs per patient were obtained by multiplying the mean resource used by the cost per unit. Cost per unit was a mean cost computed either from official databases or from pricelists from all Swedish healthcare regions. A patient fee of EUR 8.38 was added to the cost of patient days (varying costs in different regions; EUR 8-10/day).

The mean salary for Swedish women of all ages was used. Since Sweden has a minimum employee benefit, $34 \%$ was added to the salary cost. When estimating indirect costs the lost wages method was used [14].

The questionnaire included a self-reported estimation of productivity loss, but only costs derived from absenteeism were included in the results, since short-term self-reported absenteeism seem to correlate well with administrative data [15], while instruments to estimate presenteeism need further validation $[16$, 17].

Costs arising from drug consumption were calculated by asking which drugs the women had bought in the previous 12 months for the treatment of endometriosis and pain (both prescription and over-the-counter drugs) and the number of times for each type of medication. The pharmaceuticals were then grouped according to the ATC classification system, using the lowest cost for each ATC code.

To estimate the costs of surgical procedures, the women were asked to state the numbers and types of surgery. Using DRG codes 358 and 359 and operation codes for Female genital organs and Digestive system and spleen in the NOMESCO Classification of Surgical Procedures Version 1.16 with any endometriosis ICD-10 code (N80.0-N80.9) in a database containing all reported Swedish cases in 2010, the mean cost of surgery was computed. The cost of hospitalization associated with surgery was extracted, since patient days were counted as a separate cost unit.

\section{Statistical Analyses}

Based on previous studies and experiences, we assumed that a sample size of 400 women would be sufficient to provide an estimate of resource subjects. Assuming a $50 \%$ response rate, 800 questionnaires were sent out. The 400 recruited participants from the clinics were randomly selected from a larger group of patients by randomization carried out by an external statistician company 
Table 1. Demographic and descriptive data on participants subdivided after age group

\begin{tabular}{|c|c|c|c|c|}
\hline & $<30$ years & $30-39$ years & $\geq 40$ years & Total \\
\hline Age, years, $n$, mean \pm SD & 93 & 186 & 144 & 423 \\
\hline Age & $25.2 \pm 3.1$ & $35.3 \pm 2.6$ & $45.9 \pm 5.7$ & $36.7 \pm 8.7$ \\
\hline Age at first visit to a doctor due to endometriosis & $18.3 \pm 4.5$ & $23.3 \pm 7.3$ & $29.8 \pm 10.8$ & $24.2 \pm 9.3$ \\
\hline Age when diagnosed by a doctor & $22.5 \pm 3.4$ & $28.9 \pm 5.2$ & $34.3 \pm 8.3$ & $29.3 \pm 7.5$ \\
\hline Marriage status $n$ (\% of answers) & 89 & 183 & 141 & 413 \\
\hline Single & $23(26)$ & $25(14)$ & $24(17)$ & $72(17)$ \\
\hline Married/cohabitation & $52(58)$ & $148(81)$ & $99(70)$ & $299(72)$ \\
\hline Separate living & $10(11)$ & $8(4)$ & $12(9)$ & $30(7)$ \\
\hline Divorced/separated & $4(4)$ & $2(1)$ & $5(4)$ & $11(3)$ \\
\hline Widow & - & - & $1(0.1)$ & $1(0.2)$ \\
\hline Highest level of education $n$ (\% of answers) & 93 & 185 & 143 & 421 \\
\hline Primary school & $9(10)$ & $5(3)$ & $6(4)$ & $20(5)$ \\
\hline High school & $33(35)$ & $42(23)$ & $48(34)$ & $123(29)$ \\
\hline Residential college & $5(5)$ & $4(2)$ & $5(3)$ & $14(3)$ \\
\hline Vocational education & $16(17)$ & $32(17)$ & $19(13)$ & $67(16)$ \\
\hline University & $30(32)$ & $102(55)$ & $65(45)$ & $197(47)$ \\
\hline Main occupation during the previous 4 weeks $n$ (\% of answers) & 83 & 163 & 134 & 380 \\
\hline Paid employment $\geq 30 \mathrm{~h} /$ week & $33(40)$ & $101(62)$ & $76(57)$ & $210(55)$ \\
\hline Paid employment $<30 \mathrm{~h} /$ week & $14(17)$ & $12(7)$ & $13(10)$ & $39(10)$ \\
\hline Student & $21(25)$ & $9(6)$ & $2(1)$ & $32(8)$ \\
\hline Managing household tasks & $1(1)$ & $7(4)$ & $3(2)$ & $11(3)$ \\
\hline Unemployed & $2(2)$ & $2(1)$ & $4(3)$ & $8(2)$ \\
\hline Early retirement or disability pension & $2(2)$ & $3(2)$ & $16(12)$ & $21(6)$ \\
\hline Retired & - & - & $2(1)$ & $2(1)$ \\
\hline Other & $10(12)$ & $29(18)$ & $18(13)$ & $57(15)$ \\
\hline Duration of endometriosis symptoms $n$ (\% of answers) & 93 & 186 & 144 & 412 \\
\hline$<6$ months & $2(2)$ & $1(1)$ & $3(2)$ & $6(1)$ \\
\hline $6-12$ months & $5(5)$ & $3(2)$ & $2(1)$ & $10(2)$ \\
\hline $1-2$ years & $2(2)$ & $7(4)$ & $2(1)$ & $11(3)$ \\
\hline $2-5$ years & $24(26)$ & $24(13)$ & $14(10)$ & $62(15)$ \\
\hline $5-10$ years & $26(28)$ & 36 (19) & $20(14)$ & $82(20)$ \\
\hline$>10$ years & $30(32)$ & $112(60)$ & $99(69)$ & $241(58)$ \\
\hline
\end{tabular}

(Statisticon $\mathrm{AB}$ ). The study population was divided into 3 predefined age groups ( $<30,30-39$ and $\geq 40$ years).

Variables on continuous scales are described as mean, SD, and range and nominal data as frequency and percentage. In our logistic regression models, the age group 30-39 constituted the reference group. The results of logistic regression are given as ORs with 95\% CIs. The level of statistical significance was set at $p<0.05$.

IBM SPSS Statistics version 20 was used for the analyses. An external statistician conducted logistic regression analyses, using $R$ version 3.2.2. (Statisticon $A B$ ).

\section{Results}

Out of the 800 self-administered questionnaires distributed, 449 (56\%) were returned, and after correcting for doublets, 431 remained. Of the evaluable question- naires, 199 were from the 5 participating clinics and 232 were from the Endometriosis Association. The vast majority of the women recruited from the Endometriosis Association $(96.8 \%)$ reported that they had been diagnosed by a gynecologist.

A summary of patient characteristics is shown in Table 1. The mean age of all women was 36.7 years, 24.2 years at the time of the first visit to a doctor because of endometriosis-associated problems, and 29.3 at diagnosis, a delay of 5.1 years. During the past 12 months, $27 \%$ reported that they had undergone surgery for endometriosis.

The mean annual consumption of healthcare resources differed between age groups and apart from visits to fertility specialists, younger women utilized more inpatient and outpatient care. Almost half of the women under 30 years old had visited their general 
Table 2. Logistic regression with ORs and 95\% CIs for the likelihood of having used healthcare resources or receiving pharmaceutical benefit during the previous 12 months. The age group 30-39 years constitutes the reference group

\begin{tabular}{|c|c|c|c|}
\hline & OR & $95 \% \mathrm{CI}$ & $p$ value \\
\hline \multicolumn{4}{|c|}{ General practitioner, visit, years } \\
\hline$<30$ & 1.69 & $1.01-2.84$ & 0.047 \\
\hline$\geq 40$ & 1.03 & $0.65-1.65$ & 0.893 \\
\hline \multicolumn{4}{|c|}{ General practitioner, telephone contact, years } \\
\hline$<30$ & 2.36 & $1.37-4.06$ & 0.002 \\
\hline$\geq 40$ & 0.86 & $0.50-1.47$ & 0.580 \\
\hline \multicolumn{4}{|c|}{ Nurse or midwife, visit, years } \\
\hline$<30$ & 1.70 & $0.99-2.95$ & 0.056 \\
\hline$\geq 40$ & 0.31 & $0.16-0.61$ & 0.001 \\
\hline \multicolumn{4}{|c|}{ Nurse or midwife, telephone contact, years } \\
\hline$<30$ & 1.85 & $1.05-3.27$ & 0.035 \\
\hline$\geq 40$ & 0.46 & $0.24-0.88$ & 0.020 \\
\hline \multicolumn{4}{|c|}{ Gynecologist, visit, years } \\
\hline$<30$ & 1.69 & $0.88-3.25$ & 0.113 \\
\hline$\geq 40$ & 0.61 & $0.38-1.00$ & 0.051 \\
\hline \multicolumn{4}{|c|}{ Gynecologist, telephone contact, years } \\
\hline$<30$ & 1.81 & $1.07-3.07$ & 0.028 \\
\hline$\geq 40$ & 0.56 & $0.36-0.88$ & 0.012 \\
\hline \multicolumn{4}{|c|}{ Fertility specialist, visit, years } \\
\hline$<30$ & 0.32 & $0.16-0.65$ & 0.002 \\
\hline$\geq 40$ & 0.16 & $0.08-0.34$ & $<0.001$ \\
\hline \multicolumn{4}{|c|}{ Emergency room visit, years } \\
\hline$<30$ & 2.75 & $1.61-4.68$ & $<0.001$ \\
\hline$\geq 40$ & 0.60 & $0.34-1.06$ & 0.080 \\
\hline \multicolumn{4}{|c|}{ Other planned hospital visit, years } \\
\hline$<30$ & 1.44 & $0.87-2.38$ & 0.160 \\
\hline$\geq 40$ & 0.72 & $0.46-1.12$ & 0.147 \\
\hline \multicolumn{4}{|c|}{ Admission to hospital, years } \\
\hline$<30$ & 1.92 & $1.14-3.24$ & 0.015 \\
\hline$\geq 40$ & 0.63 & $0.37-1.06$ & 0.083 \\
\hline \multicolumn{4}{|c|}{ Surgery for endometriosis, years } \\
\hline$<30$ & 2.07 & $1.22-3.53$ & 0.007 \\
\hline$\geq 40$ & 0.83 & $0.49-1.40$ & 0.483 \\
\hline \multicolumn{4}{|c|}{ Pharmaceutical benefit, years } \\
\hline$<30$ & 1.67 & $1.00-2.81$ & 0.050 \\
\hline$\geq 40$ & 0.64 & $0.39-1.05$ & 0.079 \\
\hline
\end{tabular}

physician during the previous year (overall range 0-30). A majority had visited gynecologists and/or had had telephone contact. Emergency room visit frequency was high among the young, were almost half having had at least one visit, and 9\% having had $>3$ visits (overall range $0-11$ ). Moreover, $42 \%$ had been admitted to hospital and $41 \%$ had undergone surgery. Every third woman aged 30-39 years had visited a fertility specialist at some time the previous year, and almost half of women aged 30-39 had ever experienced assisted reproduction.
The higher healthcare consumption in the youngest age group was also reflected in the logistic regression analyses concerning the likelihood of having used healthcare resources or having received pharmaceutical benefit during the previous 12 months. Many of the outcomes showed statistically significant differences (see the ORs in Table 2). Younger women showed higher ORs as regards visiting (OR 1.69, 95\% CI 1.01-2.84) and having telephone contact (OR 2.36, 95\% CI 1.37-4.06) with general practitioners. They also had more telephone contacts with both nurses/midwives (OR 1.85, 95\% CI 1.05-3.27) and gynecologists (OR 1.81, 95\% CI 1.07-3.07). However, the higher odds regarding gynecologist visits were not statistically significant. They also had higher odds as regards emergency room visits (OR $2.75,95 \%$ CI 1.61-4.68, admissions to hospital (OR 1.92, 95\% CI 1.14-3.24), and surgery (OR 2.07, 95\% CI 1.22$3.53)$.

The oldest women ( $\geq 40$ years) showed lower odds as regards nurse/midwife visits (OR 0.31, 95\% CI 0.16-0.61) and telephone contacts with both nurses/midwives (OR $0.46,95 \%$ CI $0.24-0.88$ ) and gynecologists (OR 0.56, 95\% CI 0.36-0.88).

As shown in Table 3, the mean total annual cost was EUR 8,768/woman. Reduced work productivity accounted for a substantial part of the cost, as $32 \%$ of the women reported absence from work because of endometriosis, and $36 \%$ reported reduced time at the workplace because of the condition. Major direct cost drivers were hospitalization (EUR 1,438/woman/year), surgery (EUR 749/ woman/year), and visits to gynecologists (EUR 591/ woman/year). Loss of productivity was estimated to cost EUR 4,486/woman/year (Table 3).

Costs related to visits to fertility specialists were highest among women aged 30-39. All other costs were highest in the youngest age group. Women aged 30-39 showed the lowest total cost (EUR 7,702/woman/year; Table 3). Figure 1 demonstrates the distribution of direct, indirect, and pharmaceutical costs dived into the 3 age groups and the whole study population.

\section{Discussion}

The results showed that both healthcare consumption and cost estimates were highest in the youngest age group. They visited an emergency department more than once a year because of endometriosis-related symptoms, at an age where most people rarely need emergency care. Assuming a $3-5 \%$ prevalence of symptomatic endometrio- 
Table 3. Mean cost per woman per year in each age group and in the whole study population

\begin{tabular}{lcccc}
\hline & Under 30 years & 30-39 years & Over 40 years & All ages \\
\hline Direct costs, EUR & & & & \\
Visits to gynecologist & 932 & 574 & 410 & 591 \\
Visits to fertility specialist & 72 & 305 & 58 & 172 \\
Visits to emergency room & 350 & 180 & 79 & 183 \\
Other planned hospital visits & 455 & 250 & 239 & 288 \\
Visits to general practitioner & 259 & 164 & 153 & 179 \\
Visits to nurse or midwife & 65 & 40 & 15 & 36 \\
Telephone contact with general practitioner & 184 & 70 & 97 & 102 \\
Telephone contact with gynecologist & 465 & 264 & 177 & 275 \\
Telephone contact with nurse or midwife & 132 & 89 & 36 & 79 \\
Cost of inpatient care-based patient days & 2,022 & 1,358 & 1,227 & 1,438 \\
Pharmaceuticals, and so on & 18 & 14 & 9 & 13 \\
Pharmaceuticals, prescription & 78 & 44 & 15 & 41 \\
Pharmaceuticals, benefit & 193 & 141 & 101 & 136 \\
Surgery & 1,203 & 658 & 635 & 749 \\
Indirect costs, EUR & & & & \\
$\quad$ Loss of productivity & 6,172 & 3,553 & 4,773 & 4,486 \\
\hline Total, EUR & 12,601 & 7,702 & 8,025 & 8,768 \\
\hline
\end{tabular}

sis in women of fertile age (15-50 years), our data suggest that 39,000-65,000 emergency department visits could be related to endometriosis annually in Sweden.

There are several possible reasons why younger women with endometriosis showed higher healthcare consumption than older women. First, younger women might not have developed strategies to manage their symptoms on their own to the same extent as women with a longer disease experience. Second, younger women are probably more likely to find information on the internet where they might be encouraged to seek care. It might also be that younger women do not accept pain symptoms as a normal state and they become active care seekers.

The high healthcare consumption among the young is concordant with the results of another Swedish study based on data from the same questionnaire as described herein, where young women with endometriosis experienced more symptoms and had a lower quality of life compared with older women [11].

Women of 30-39 years of age stood out in 2 areas. They had the lowest mean level of absence from work and were the most likely to have paid visits to fertility specialists. The latter observation was expected, since in Sweden, women in the other age groups often have a lower wish to conceive. However, we were surprised to find the lowest mean level of sick leave in this age group. The results might be affected by a high rate of pregnancies, childbirth, and periods of breast-feeding and parental leave in

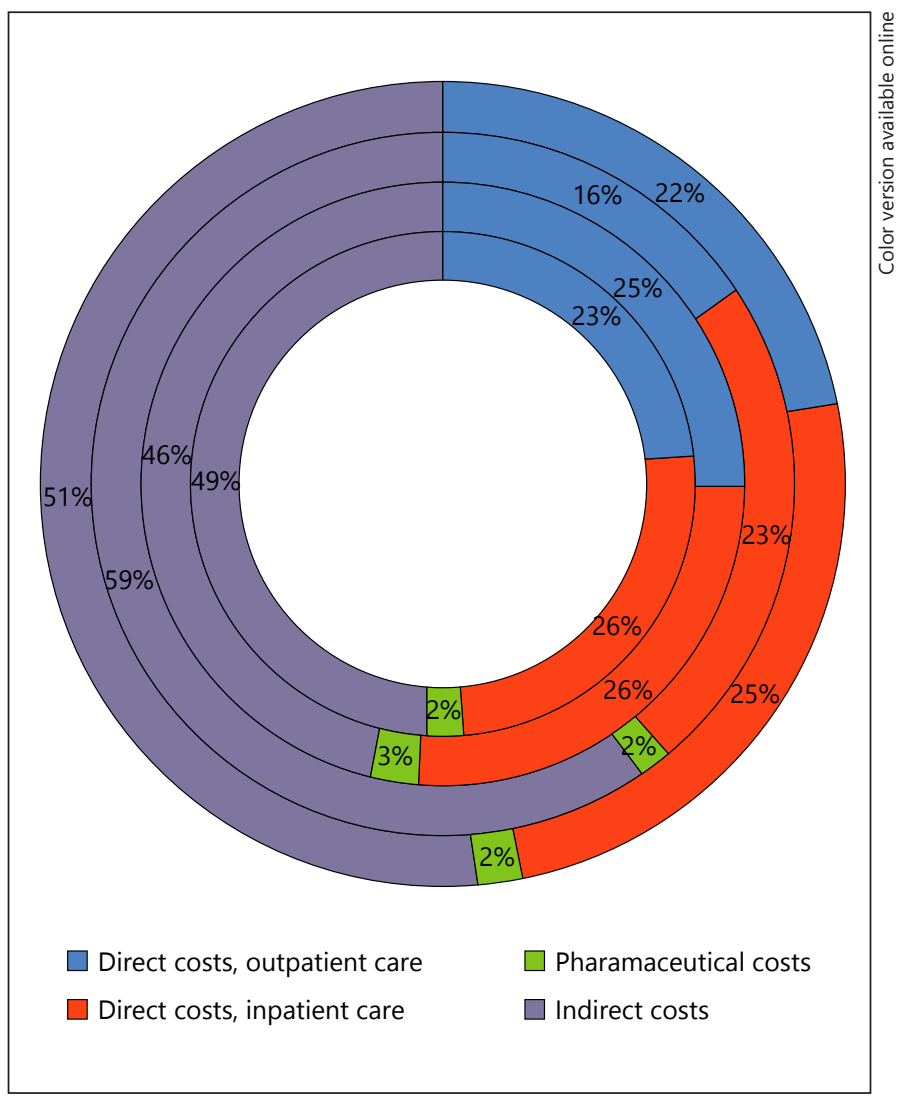

Fig. 1. Donut chart: inner to outer circle representing women of $<30$ years, $30-39$ years, $\geq 40$ years, and the whole study population, respectively. 
the 30-39-year age group, leading to less sick leave, as the women may already be absent for other reasons. Another possible explanation may be that women in this age group are at a stage of their professional careers where they are more unwilling to be on sick leave.

Diagnostic delay was found to be around 5 years. This was measured as doctor's delay, from the first visit to a doctor because of presumed endometriosis-related symptoms until being diagnosed with endometriosis. Diagnostic delays also generate additional costs, as women with endometriosis utilize more healthcare than controls, both before and after diagnosis [18]. By improving diagnostics and raising awareness of the condition, both among women and physicians, recognition and diagnostic delay could be reduced, perhaps letting women come to terms with their sickness at an earlier stage and start developing coping mechanisms. This might increase productivity and result in better quality of life.

The high costs of endometriosis care are well in line with what previously has been shown, where reduced work productivity and direct in-patient costs, including surgery, are identified as the major cost drivers [10]. Women in the youngest age group generated over $60 \%$ higher costs compared with the older women. Because of the chronic nature of the disease, one would expect that the symptoms, and therefore the cost, would progress with age. A possible explanation for our results is that the older women might have developed coping mechanisms over time that could decrease the impact of the symptoms. This has also been suggested earlier [19, 20].

Many women in the study had undergone assisted reproduction. The need for assisted reproduction among endometriosis patients is well known, as infertility affects $30-50 \%$ of all women with endometriosis. They are also at higher risk of decreased ovarian reserve, as a result of the disease pathophysiologic mechanisms [21].

The direct cost EUR 4,282 can be compared with data published by the Swedish Association of Local Authorities and Regions, wherein they reported an annual healthcare direct cost of EUR 1,951 for an average female Swede. Our total annual cost of EUR 8,768/woman can also be compared with other recent Swedish studies reporting annual costs in other benign persistent conditions: annual total cost of migraine was EUR 10,790 (EUR rate 2013) per patient [22], annual total cost of Irritable bowel syndrome with predominant constipation was EUR 12,873 (EUR rate 2019) per patient [23], and mean total cost of low back pain was EUR 2,753 (EUR rate 2016) per episode [24].
The indirect cost of reduced work productivity contributed less to the total cost compared with what others have shown, $46-59$ vs. $66 \%$ [25] and 78\% [26]. In contrast, Prast et al. [27] estimated a figure of only $27 \%$ of total cost due to loss of productivity. These differences might arise from methodological differences as well as different social security systems. Costs arising from presenteeism are excluded from our results, which is likely to have led to underestimation of the total cost, and is a limitation of the study. Furthermore, we did not include indirect cost like transportation and so on, which also may result in an underestimation of the cost.

To obtain healthcare consumption and cost estimates not only from women with the most severe symptoms, we included women with surgically verified disease as well as women from the Endometriosis Association who have self-reported endometriosis. This can be considered both as a strength, since they are more likely to represent the less severe endometriosis patients not having had a need of surgery, and a weakness, considering the risk of including women without endometriosis. This constrains us from making any comparisons between the groups. Another limitation is that the inclusion of women from the Endometriosis Association might have resulted in a selected group of individuals more driven and interested in their own health, which in turn might affect the results. Also, we did not study the relation of severity and duration of endometriosis to costs, which may have provided an interesting dimension to the results.

The response rate (56\%) may seem low, but since we sent out 800 questionnaires, we had a lot of answers even with the relatively low rate. A response rate $>50 \%$ is generally considered acceptable [28]. A reminder was sent to participants who did not answer the first questionnaire.

Among our responders, there was a high amount of women with a university degree, which is not representative of the total Swedish population. Because of differences in healthcare systems and socioeconomic variance, the cost estimates may be of limited generalizability.

In conclusion, we as well as others have shown that women with endometriosis show a high level of healthcare consumption, leading to high direct costs. We have now, for the first time, shown that women under 30 years of age with endometriosis consume more healthcare resources, thus leading to higher costs per year compared with women over 30 years.

Increased awareness of endometriosis among healthcare professionals as well as the general population is of public interest, as awareness may prevent diagnostic de- 
lays and thereby not only lead to decreased costs but also to an improvement the quality of life for a large group of women in their prime years. Since a majority of women with endometriosis experience symptom relief with relatively cheap drugs, such as over-the-counter analgesics and hormones, and the current recommendation is to suppress symptoms even without a definite diagnosis, increased awareness could also diminish costs by reducing surgical procedures. Furthermore, clinic should probably strive toward working in multiprofessional teams around the most complicated cases. This could strengthen the bio-psycho-social caring aspects of this chronic disease, which may lead to less healthcare consumption and costs.

Future studies could focus on women's experiences of the quality of endometriosis healthcare and on what aspects of endometriosis care may be most cost-effective to improve in relation to experiences, personal suffering, and economic burden.

\section{Acknowledgment}

The authors would like to thank Per Boström for excellent assistance with health economic aspects of the work.

\section{Statement of Ethics}

The study was approved by the Ethics Review Board in Uppsala, Sweden (Dnr 2010/216), which ensures that it complies with the guidelines for human studies and was conducted in accordance with the Word Medical Association Declaration of Helsinki.

\section{Disclosure Statement}

A larger study, on which this paper is based, was carried out in association with Bayer Healthcare 2009-2010. Bayer has legal rights to the questionnaire and data used in this paper. Lena Lövqvist was employed by Bayer at the time of the study.

\section{Funding Sources}

The study was funded by Bayer Healthcare.

\section{Author Contributions}

H.G. and G.H.S. contributed equally to this work. G.H.S., L.L., and M.O. designed the study and collected data. All authors conduced the analyses and discussed results and conclusions. H.G. was the leading writer of the manuscript, but all authors contributed in the writing. The final version was approved by all authors.

\section{References}

1 Dunselman GA, Vermeulen N, Becker C, Calhaz-Jorge C, D’Hooghe T, De Bie B, et al.; European Society of Human Reproduction and Embryology. ESHRE guideline: management of women with endometriosis. Hum Reprod. 2014 Mar;29(3):400-12.

2 Adamson D, Kennedy S, Hummelshoj L. Creating solutions in endometriosis: global collaboration through the World Endometriosis Research Foundation. J Endometr. 2010;2(1): 3-6.

3 Laganà AS, Garzon S, Götte M, Viganò P, Franchi M, Ghezzi F, et al. The pathogenesis of endometriosis: molecular and cell biology insights. Int J Mol Sci. 2019 Nov;20(22):5615.

4 Nnoaham KE, Hummelshoj L, Webster P, d'Hooghe T, de Cicco Nardone F, de Cicco Nardone C, et al.; World Endometriosis Research Foundation Global Study of Women's Health consortium. Impact of endometriosis on quality of life and work productivity: a multicenter study across ten countries. Fertil Steril. 2011 Aug;96(2):366-373.e8.

5 Greene R, Stratton P, Cleary SD, Ballweg ML, Sinaii N. Diagnostic experience among 4,334 women reporting surgically diagnosed endometriosis. Fertil Steril. 2009 Jan;91(1):32-9.

6 Hudelist G, Fritzer N, Thomas A, Niehues C, Oppelt P, Haas D, et al. Diagnostic delay for endometriosis in Austria and Germany: causes and possible consequences. Hum Reprod. 2012 Dec;27(12):3412-6.

7 Soliman AM, Fuldeore M, Snabes MC. Factors associated with time to endometriosis diagnosis in the United States. J Womens Health (Larchmt). 2017 Jul;26(7):788-97.

8 Simoens S, Hummelshoj L, D’Hooghe T. Endometriosis: cost estimates and methodological perspective. Hum Reprod Update. 2007 Jul-Aug;13(4):395-404.

9 Gao X, Outley J, Botteman M, Spalding J, Simon JA, Pashos CL. Economic burden of endometriosis. Fertil Steril. 2006 Dec;86(6): 1561-72.

10 Soliman AM, Yang H, Du EX, Kelley C, Winkel C. The direct and indirect costs associated with endometriosis: a systematic literature review. Hum Reprod. 2016 Apr;31(4):712-22.

11 Lövkvist L, Boström P, Edlund M, Olovsson $M$. Age-related differences in quality of life in Swedish women with endometriosis. J Womens Health (Larchmt). 2016 Jun;25(6):64653.

12 Taft C, Karlsson J, Sullivan M. Performance of the Swedish SF-36 version 2.0. Qual Life Res. 2004 Feb;13(1):251-6.

13 Jones G, Kennedy S, Barnard A, Wong J, Jenkinson C. Development of an endometriosis quality-of-life instrument: The Endometriosis Health Profile-30. Obstet Gynecol. 2001 Aug;98(2):258-64.

14 Berger ML, Murray JF, Xu J, Pauly M. Alternative valuations of work loss and productivity. J Occup Environ Med. 2001 Jan;43(1): $18-24$.

15 Short ME, Goetzel RZ, Pei X, Tabrizi MJ, Ozminkowski RJ, Gibson TB, et al. How accurate are self-reports? Analysis of selfreported health care utilization and absence when compared with administrative data. J Occup Environ Med. 2009 Jul;51(7):78696.

16 Ospina MB, Dennett L, Waye A, Jacobs P, Thompson AH. A systematic review of measurement properties of instruments assessing presenteeism. Am J Manag Care. 2015 Feb; 21(2):e171-85.

17 Thompson AH, Waye A. Agreement among the productivity components of eight presenteeism tests in a sample of health care workers. Value Health. 2018 Jun;21(6):650-7.

18 Fuldeore M, Yang H, Du EX, Soliman AM, Wu EQ, Winkel C. Healthcare utilization and costs in women diagnosed with endometriosis before and after diagnosis: a longitudinal analysis of claims databases. Fertil Steril. 2015 Jan;103(1):163-71.
Endometriosis Healthcare Consumption and Cost Estimates in Sweden
Gynecol Obstet Invest 2020;85:237-244 DOI: $10.1159 / 000507326$ 
19 Grogan S, Turley E, Cole J. 'So many women suffer in silence': a thematic analysis of women's written accounts of coping with endometriosis. Psychol Health. 2018 Nov;33(11):1364-78.

20 Zarbo C, Brugnera A, Frigerio L, Malandrino C, Rabboni M, Bondi E, et al. Behavioral, cognitive, and emotional coping strategies of women with endometriosis: a critical narrative review. Arch Women Ment Health. 2018 Feb;21(1):1-13.

21 Terzic M, Aimagambetova G, Garzon S, Bapayeva G, Ukybassova T, Terzic S, et al. Ovulation induction in infertile women with endometriotic ovarian cysts: current evidence and potential pitfalls. Minerva Med. 2019, Epub ahead of print.
22 Hjalte F, Olofsson S, Persson U, Linde M. Burden and costs of migraine in a Swedish defined patient population - a questionnaire-based study. J Headache Pain. 2019 May;20(1):65.

23 Tack J, Stanghellini V, Mearin F, Yiannakou Y, Layer P, Coffin B, et al.; IBIS-C Study group. Economic burden of moderate to severe irritable bowel syndrome with constipation in six European countries. BMC Gastroenterol. 2019 May;19(1):69.

24 Olafsson G, Jonsson E, Fritzell P, Hägg O, Borgström F. Cost of low back pain: results from a national register study in Sweden. Eur Spine J. 2018 Nov;27(11):2875-81.

25 Simoens S, Dunselman G, Dirksen C, Hummelshoj L, Bokor A, Brandes I, et al. The bur- den of endometriosis: costs and quality of life of women with endometriosis and treated in referral centres. Hum Reprod. 2012 May; 27(5):1292-9.

26 Levy AR, Osenenko KM, Lozano-Ortega G, Sambrook R, Jeddi M, Bélisle S, et al. Economic burden of surgically confirmed endometriosis in Canada. J Obstet Gynaecol Can. 2011 Aug;33(8):830-7.

27 Prast J, Oppelt P, Shamiyeh A, Shebl O, Brandes I, Haas D. Costs of endometriosis in Austria: a survey of direct and indirect costs. Arch Gynecol Obstet. 2013 Sep;288(3):56976.

28 Field A. Discovering statistics using IBM SPSS statistics. 4. Los Angeles: Sage; 2013. 